\title{
Anti-oxidant treatment prevents the development of peripheral nerve dysfunction in streptozotocin-diabetic rats
}

\author{
N.E.Cameron, M.A.Cotter and E.K.Maxfield \\ Department of Biomedical Sciences, University of Aberdeen, Aberdeen, Scotland
}

\begin{abstract}
Summary. We tested the notion that oxidative stress makes an important contribution to the aetiology of diabetic neuropathy. The effect of treatment with a $1 \%$ dietary supplement of the anti-oxidant butylated hydroxytoluene was studied during 2 months of streptozotocin-induced diabetes mellitus. In final experiments, sciatic motor and saphenous sensory conduction velocities were measured in vivo, and resistance to hypoxic conduction failure for sciatic trunk was examined in vitro. There were $20 \%$ and $12 \%$ decreases in motor and sensory conduction velocity, respectively after 2 months of diabetes $(p<0.001)$. These were completely prevented by butylated hydroxytoluene treatment $(p<0.001)$. Resistance to hypoxic conduction failure, shown by the time taken for sciatic compound action potential amplitude to decline by $80 \%$, was $55 \%$ increased by diabetes,
\end{abstract}

and this was limited to $31 \%(p<0.01)$ by treatment. There were no significant effects of treatment on the 9-10 fold elevation of sciatic nerve sorbitol and fructose levels with diabetes, or on the non-significant $22 \%$ reduction in myoinositol content. Butylated hydroxytoluene treatment also did not affect sciatic nerve capillary density. We conclude that oxidative stress makes an important contribution to the aetiology of early experimental diabetic neuropathy. Amelioration of oxidative stress could potentially be a final common mechanism whereby a number of diverse treatments exert a beneficial effect on diabetic nerve function.

Key words: Neuropathy, nerve conduction, ischaemic resistance, oxidative stress, butylated hydroxytoluene, polyol pathway, streptozotocin, diabetic rat.
An early reduction in nerve conduction velocity (NCV) and an increase in resistance to ischaemic conduction failure (RICF) are observed in rats following induction of diabetes mellitus. An important aetiological contribution comes from the vascular effects of diabetes, leading to hypoperfusion of the vasa nervorum and the development of a hypoxic microenvironment for neurons and Schwann cells [1]. Nerve dysfunction may be prevented or corrected by vasodilator treatment which restores endoneurial blood flow [2-5]. However, other seemingly unrelated treatments are also effective and a number of alternative mechanisms have been suggested to underlie the aetiology of diabetic neuropathy. Thus, nerve function is improved by chronic electrical stimulation [6], evening primrose oil [7-9], aminoguanidine $(10,11)$, and aldose reductase inhibitors $[12,13]$. Evening primrose oil is a complex natural product which could have several potential actions ranging from alterations in cell membrane fluidity to promotion of vasoactive prostanoid synthesis [7]. Aminoguanidine inhibits the formation of advanced glycation end-products $[10,14,15]$. Under some conditions aminoguanidine can also function as an aldose re- ductase inhibitor [16] and has also been suggested to be an inhibitor of nitric oxide synthase [17]. Aldose reductase inhibitors reduce the metabolic consequences of elevated polyol pathway flux $[12,13]$. They may also correct abnormalities in phosphoinositide metabolism and nerve $\mathrm{Na}^{+}$$\mathrm{K}^{+}$-ATPase activity [18], although considerable doubt has been cast over these putative effects $[3,19,20]$. Aldose reductase inhibitors may also have vascular actions, which improve nerve blood flow [21] and vascular smooth muscle relaxation [22].

Thus, multiple therapeutic strategies correct nerve dysfunction in the early stages of experimental diabetes. It is possible to argue that a vascular action underlies at least some of these diverse treatments, and a common endpoint may be the amelioration of oxidative stress. Several factors promote oxidative stress in diabetes, including nerve ischaemia-reperfusion $[23,24]$, increased free radical production caused by autoxidation reactions of sugars with proteins and unsaturated lipids [14], and impairment of tissue anti-oxidant protection systems [25-27].

Anti-oxidants such as glutathione, vitamin $\mathrm{E}$, and butylated hydroxy toluene (BHT) prevent or slow the develop- 


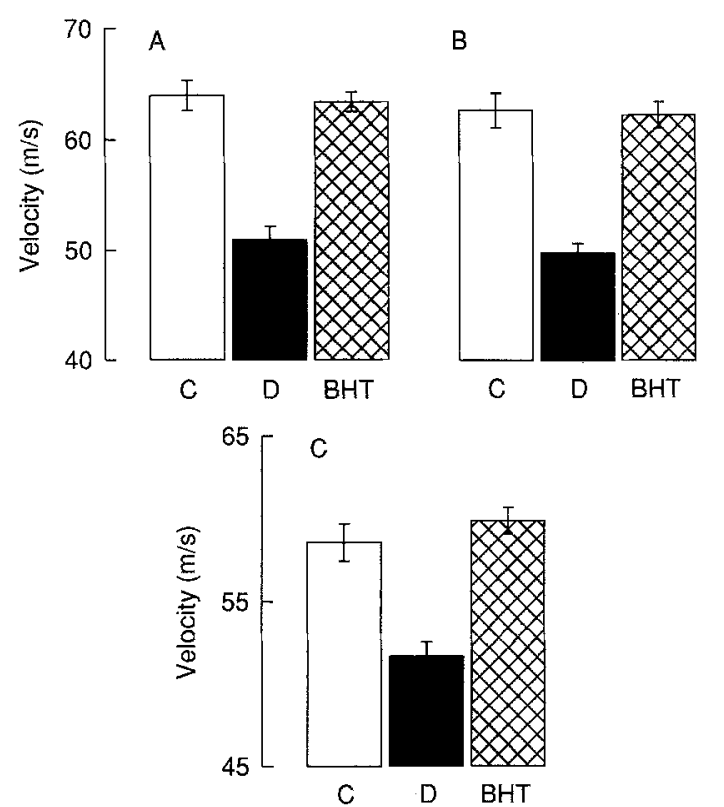

Fig. $1 \mathbf{A}-\mathbf{C}$. Conduction velocity in sciatic motor nerves supplying $\mathbf{A}$, gastrocnemius; $\mathbf{B}$, tibialis anterior muscles; and $\mathbf{C}$, sensory saphenous nerve. Bars show means \pm SEM. C, Control rats, $n=20 ; \mathrm{D}$, diabetic control rats, $n=19$; BHT, butylated hydroxytoluene-treated diabetic rats, $n=11$. Statistical analysis: for all three NCV measurements D vs C, $p<0.001$; D vs BHT, $p<0.001$; BHT vs C, NS

ment of opacity in rats lenses exposed to high glucose or galactose concentrations in vitro and in vivo, with little effect on the accumulation of polyol pathway metabolites [28-31]. Cumulative cell damage due to oxidative stress could be responsible for the progressive deterioration of function in tissues other than lens in diabetes [14]. To test the applicability of this hypothesis to peripheral nerve, the effect of a BHT dietary supplement in preventing NCV and RICF abnormalities was examined during 2 months of streptozotocin-induced diabetes.

\section{Materials and methods}

All experiments were carried out on mature male Sprague-Dawley rats (Aberdeen University colony), 19 weeks old at the start of the study. One group of non-diabetic rats was used as controls. Two other groups were given $40 \mathrm{mg} / \mathrm{kg}$ i.p. streptozotocin (Sigma, Poole, Dorset, UK) in $20 \mathrm{mmol} / \mathrm{l}$ sodium citrate buffer $(\mathrm{pH} \mathrm{4.5)}$. Diabetes was verified $24 \mathrm{~h}$ later by estimating hyperglycaemia and glycosuria (Visidex II and Diastix; Ames, Slough, Bucks., UK), and was monitored at weekly intervals. Body weights were measured daily, and rats were rejected if blood glucose levels in the fed state were less than $20 \mathrm{mmol} / \mathrm{l}$, or if there was a sustained increase in body weight over 3 consecutive days. Samples for non-fasted plasma glucose measurement using a standard test kit (GOD-Period method; Boehringer Mannheim, Mannheim, FRG) were taken on the day of final experiments. One group of diabetic rats was untreated for 2 months to act as diabetic controls. The other diabetic group was treated with a $1 \%$ BHT (Sigma) dietary supplement added to the rat chow. BHT treatment proved to have a partial protective effect against induction of diabetes by streptozotocin. In a first group of 12 rats, treatment was started immediately following streptozotocin injection and, al though all animals showed varying degrees of hyperglycaemia, six rats failed to reach a criterion plasma glucose of $20 \mathrm{mmol} / \mathrm{l}$ or more and were rejected from the experiment. In a second group of six rats, treatment was started 3 days after diabetes in- duction and only one rat was rejected as not being sufficiently diabetic, which is not exceptional. The early protective effect of BHT on diabetes induction is likely to be due to neutralisation of free radical production by streptozotocin, which is thought to underlie the destruction of beta cells [32].

In final experiments (1-1.5 g/kg i. p. urethane anaesthesia), NCV was measured in vivo between sciatic notch and knee for motor branches supplying tibialis anterior and gastrocnemius muscles. Sensory NCV was measured in the saphenous nerve between groin and ankle. Methods have been previously described in detail [13].

RICF was measured in vitro as previously described [7]. Briefly, the sciatic trunk was removed and mounted on bipolar stimulating (proximal) and recording (distal) electrodes. The nerve was equilibrated in Krebs' solution at $35^{\circ} \mathrm{C}$ gassed with $95 \% \mathrm{O}_{2} / 5 \% \mathrm{CO}_{2}$ for $30 \mathrm{~min}$, and then transferred to mineral oil pre-gassed with $100 \% \mathrm{~N}_{2}$ for $1 \mathrm{~h}$. Nerves were stimulated with supramaximal pulses $(1 \mathrm{~Hz}$, $50 \mu$ s width, $10 \mathrm{~mA}$ ) and compound action potential amplitude was monitored at 2 -min intervals until it fell below $10 \%$ of its initial value.

Nerve capillarization was estimated from $10 \mu \mathrm{m}$ frozen sections of sciatic trunk in which the capillary endothelium was stained for alkaline phosphatase, as previously described [7]. Fascicle outlines were traced on a projection microscope and their areas were measured with a digitizing pad linked to a microcomputer to calcu late capillary density.

Sciatic nerve sugars and polyols were determined by gas chromatography of trimethylsilyl derivatives prepared from aqueous deproteinized extracts [33]

\section{Statistical analysis}

Data are expressed as means \pm SEM. One way analysis of variance was performed, and any significant $(p<0.05)$ differences were assigned to individual between-group comparisons using Student's $t$-tests, applying the Bonferroni correction for multiple comparisons (Instat; GraphPad, San Diego, Calif., USA).

\section{Results}

Diabetic control and BHT-treated diabetic groups had final plasma glucose levels of $32.6 \pm 2.3$ and $28.7 \pm 1.7 \mathrm{mmol} / \mathrm{l}$, respectively compared to a control value of $7.2 \pm 0.2 \mathrm{mmol} / \mathrm{l}$. Both diabetic groups lost weight, from a starting weight of $485 \pm 9$ to $370 \pm 9 \mathrm{~g}$ for diabetic control rats, and from $489 \pm 11 \mathrm{~g}$ to $376 \pm 10 \mathrm{~g}$ for BHT-treated rats.

Measurements of NCV are shown in Figure 1. For motor nerves supplying tibialis anterior (Fig.1A) and gastrocnemius (Fig. 1B) muscles, NCV was reduced by $20.5 \%$ on average compared with onset controls ( $p<0.001$ for both branches). BHT treatment completely prevented this decline in NCV $(p<0.001)$, values remaining at the onset control level. Previous work has shown that no significant increase in NCV over the 2-month experimental period would be expected in controls [13]. For sensory fibres in saphenous nerve (Fig.1C) there was an $11.7 \%$ reduction in $\mathrm{NCV}$ after 2 months diabetes $(p<0.001)$. However, with BHT treatment, sensory NCV was in the non-diabetic range, significantly improved compared to untreated diabetes $(p<0.001)$.

Data for hypoxic resistance, measured in vitro, are plotted in Figure 2. There were no significant differences in initial compound action potential amplitude between the three groups, which were $3.5 \pm 0.3,4.0 \pm 0.4$, and 


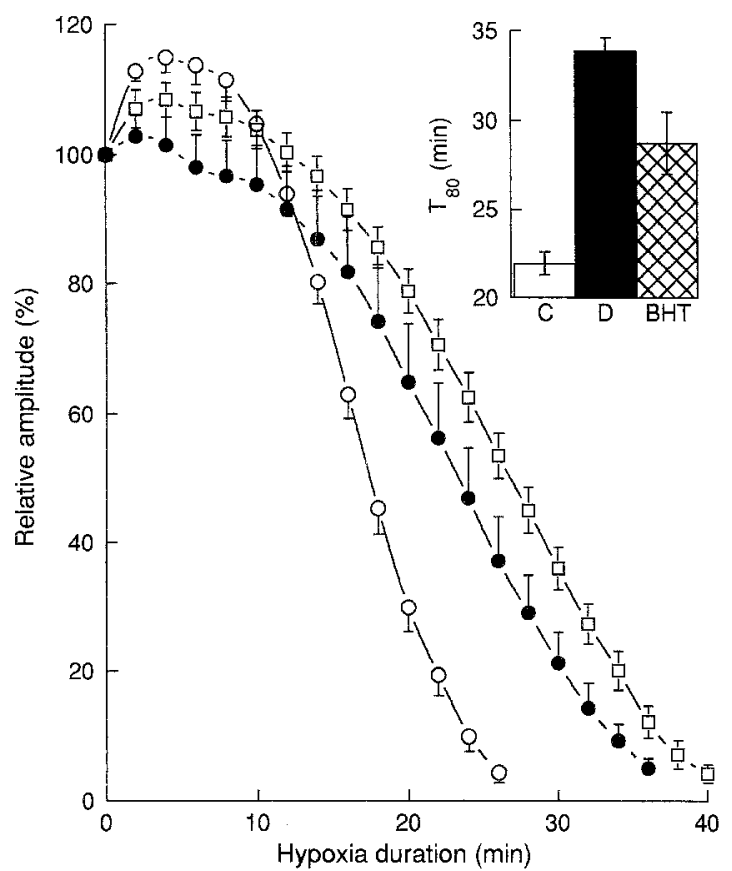

Fig. 2. Percentage change in sciatic nerve compound action potential amplitude with duration of hypoxia in vitro. Symbols and error bars show group means \pm SEM. Control rats $(O), n=20$; diabetic control rats $(\square), n=19$, butylated hydroxytoluene-treated diabetic rats (๑), $n=11$. The inset histogram shows the durations of hypoxia taken for compound action potential amplitude to decline by $80 \%$ $\left(\mathrm{T}_{80}\right)$ for control (C), diabetic control (D), and the butylated hydroxytoluene-treated diabetic rats (BHT). Statistical analysis: D vs C, $p<0.001$; D vs BHT, $p<0.01$; BHT vs $\mathrm{C}, p<0.001$

$2.9 \pm 0.2 \mathrm{mV}$, respectively for control, diabetic and BHTtreated diabetic animals. With increasing hypoxia duration, compound action potential amplitude declined after an initial period of hyperexcitability [34]. The rate of decline was much more rapid in nerves from control than diabetic rats. Relative compound action potential amplitude was significantly $(p<0.05)$ elevated by untreated diabetes at all time points sampled from $16 \mathrm{~min}$. For the BHT-treated diabetic group, compound action potential amplitude was reduced at a rate between that of nondiabetic and diabetic controls. The BHT-treated diabetic group showed significant $(p<0.05)$ differences from the diabetic control group at all time points after $22 \mathrm{~min}$. The inset histogram in Figure 2 shows hypoxia durations for an $80 \%$ decline in compound action potential amplitude $\left(\mathrm{T}_{80}\right)$, calculated by linear interpolation from the curves for individual nerves. $\mathrm{T}_{80}$ was $55 \%$ elevated by diabetes $(p<0.001)$ but this was restricted to $31 \%$ by BHT treat- ment ( $p<0.001$ vs non-diabetic control group; $p<0.01$ vs diabetic control group).

Table 1 shows data for sciatic nerve capillary density and polyol levels. Endoneurial capillary density was unaffected by diabetes compared to control values and BHT treatment had no significant effect on capillarization. Sorbitol and fructose levels were elevated nine- and ten-fold by diabetes. BHT treatment had no significant effect. There was a $22 \%$ deficit in myo-inositol with diabetes which did not attain statistical significance and was unaffected by treatment.

\section{Discussion}

The data clearly demonstrate that anti-oxidant treatment with BHT largely prevents the development of nerve dysfunction in experimental diabetes. The effect occurred in the absence of changes in nerve polyol pathway metabolites or endoneurial capillarization, suggesting that BHT was not acting as an aldose reductase inhibitor $[12,13]$ or a general vasodilator $[3,4]$. When treatment was instigated after the action of streptozotocin was completed, BHT had no effect on the severity of diabetes, shown by plasma glucose levels, body weight loss and sciatic nerve polyol concentrations. A recent report [35] suggests that antioxidant treatment with glutathione also partially prevents the development of reduced NCV.

Neurological changes in experimental diabetes are unlikely to result from a cytotoxic action of streptozotocin, for example due to free radical activity, as they are prevented by insulin treatment [36] and are also found in pancreotomised [37] or spontaneously diabetic rats [38, 39]. Streptozotocin is rapidly metabolised [32] and any direct effect would be expected to occur while it was present in the circulation. However, NCV changes in our model develop slowly over 4 weeks [13]. Furthermore, electrical stimulation and some pharmacological treatments rapidly and reversibly correct NCV deficits even after several months of streptozotocin-diabetes $[6,40]$.

The effects of BHT on NCV and RICF are properties shared with several other treatments, including vasodilators $[3,4]$, chronic electrical stimulation $[6,41]$, evening primrose oil [7], and aldose reductase inhibitors [42, 43]. Aminoguanidine improved NCV but not RICF $[10,11]$. The mechanism(s) underlying these diabetic deficits are controversial. Lattimer and co-workers [18] suggested that both NCV and RICF abnormalities are caused by elevated polyol pathway flux, reduced myo-inositol in-

Table 1. Sciatic nerve capillary density and polyol levels in rats

\begin{tabular}{|c|c|c|c|c|}
\hline \multirow[t]{2}{*}{ Group } & \multirow{2}{*}{$\begin{array}{l}\text { Capillary density } \\
\left(\mathrm{mm}^{-2}\right)\end{array}$} & Sorbitol & Fructose & Myo-inositol \\
\hline & & \multicolumn{2}{|l|}{ ( $\mu$ mol/g nerve wet weight) } & \\
\hline Control $(n=10)$ & $61.21 \pm 1.51$ & $0.156 \pm 0.011$ & $0.456 \pm 0.039$ & $2.298 \pm 0.116$ \\
\hline $\begin{array}{l}\text { Butylated hydroxytoluene- } \\
\text { treated diabetic }(n=10)\end{array}$ & $60.52 \pm 2.57$ & $0.931 \pm 0.192^{\mathrm{a}}$ & $3.897 \pm 0.683^{b}$ & $1.759 \pm 0.250$ \\
\hline
\end{tabular}

${ }^{\mathrm{a}} \mathrm{p}<0.01,{ }^{\mathrm{b}} \mathrm{p}<0.001$ compared to control group

Data are group means \pm SEM. 
corporation into membrane phosphoinositides, and impaired $\mathrm{Na}^{+}-\mathrm{K}^{+}$-ATPase activity. The results for BHT, in common with those for some vasodilators [3,4], evening primrose oil [9], and aminoguanidine [11] do not support this hypothesis as no effects on polyol pathway metabolites or nerve myo-inositol were noted, and where studied, $\mathrm{Na}^{+}-\mathrm{K}^{+}$-ATPase activity was not improved $[3,44]$. A more plausible hypothesis is that $\mathrm{NCV}$ and $\mathrm{RICF}$ changes result from reductions in nerve blood flow leading to endoneurial hypoxia $[3,45]$. Correction of blood flow by vasodilator treatment restores NCV in diabetic rats [2]. Increased RICF may reflect an adaptation to endoneurial hypoxia, which depends on greater reliance on anaerobic metabolism [3, 45]. Once established, the phenomenon is not readily reversible by vasodilator or aldose reductase inhibitor treatments [3,43], although further progression is slowed. However, electrical stimulation to increase nerve activity, which would increase reliance on oxidative metabolism [46], does reverse RICF [41]. The data suggest that amelioration of oxidative stress could provide a common mechanism to account for the functional effects of these diverse manipulations on diabetic nerve.

There are several causes of increased oxidative stress in diabetes. Elevated polyol pathway activity decreases glutathione levels because glutathione reductase requires NADPH [47]. Aldose reductase also uses NADPH, thus, there is competition for available co-factor. Glutathione is a substrate for the glutathione peroxidase-mediated neutralization of hydroperoxides. In addition, levels of superoxide dismutase, an important anti-oxidant enzyme, are reduced by diabetes $[26,27]$ and this is related to changes in glutathione. Impaired blood flow would also contribute, as endoneurial hypoxia would increase production of oxygen free radicals via xanthine oxidase [24].

Nerve dysfunction in diabetes as a result of increased free radical activity could arise because of direct effects on neurons and Schwann cells, or indirectly by actions on their microenvironment and vascular supply or both. Direct effects could involve an increase in lipid peroxidation of axonal and Schwann cell membranes resulting in impaired function. Low and co-workers $[10,27]$ found increases in sciatic nerve conjugated dienes with streptozotocin-diabetes. Important membrane proteins could also be damaged, or modified in conjunction with hyperglycaemia, as oxidative stress increases the rate of formation of advanced glycation end-products [14]. Whilst these products have been demonstrated to accumulate in myelin [48], there is at present no evidence that they have a functional effect. However, McLean and coworkers [49] have shown non-enzymatic glycation of sciatic nerve tubulin in experimental diabetes, which could have important consequences for axonal transport and integrity.

There is substantial evidence for potentially relevant vascular effects of oxidative stress, which may act at several levels. LDL, which is elevated in diabetes, inhibits endothelium-dependent relaxation of vascular tissue [50]. When oxidised, lipoproteins are cytotoxic to many cell types including endothelial cells [51]. BHT, which is highly lipid soluble, is effective in preventing LDL oxi- dation and subsequent endothelial cell toxicity [52]. Oxidised LDL may also play an important role in the development of atherosclerosis in diabetes [53]. Thus, resistance vessel atherosclerosis, and endothelial damage which develops early in experimental diabetes [54], could contribute to the reduction in endothelial synthesis of local vasodilators and platelet anti-aggregants such as nitric oxide and prostacyclin [22, 55-58]. In addition, high levels of lipid hydroperoxides inhibit the cyclooxygenase-mediated synthesis of prostacyclin [59], and superoxide destroys nitric oxide [60]. The reduction in acetylcholine-stimulated endothelium-dependent relaxation in diabetic rat aorta in vitro may be partially compensated by addition of superoxide dismutase to the bathing fluid [61]. Endothelium of vessels from diabetic rats shows enhanced sensitivity to oxygen free radical damage, indicating reduced anti-oxidant protection [25, 55]. Moreover, vessel basement membrane thickening may be promoted by oxidative stress in combination with glycation because of cross linking of long-lived structural proteins [14].

Thus, it is likely that oxidative stress affects neurons and Schwann cells directly, and indirectly via vascular effects. The latter may introduce a deleterious positive feedback element because ischaemia-reperfusion [24] would cause oxidative stress to further damage small vessels.

The mechanisms of action of some therapeutic interventions in diabetic rats may be viewed against this background. Prevention and reversal of NCV deficits by vasodilators [2-5] compensate for the reduction in local endothelium-dependent vasodilation because of deficits in nitric oxide $[22,55-57,61-63]$ and prostacyclin release [58], as well as counteracting increased vascular reactivity to catecholamines [64] and the vasoconstrictor effect of elevated levels of angiotensin converting enzyme [65]. Chronic electrical stimulation may also produce vascular benefits [6] as it increases nerve blood flow [66]. Evening primrose oil may provide substrate for vasodilator prostanoid synthesis [7] to compensate for the deficit in prostacyclin release [58]. Aminoguanidine inhibits the formation of advanced glycation end-products [14], and prevents their "quenching" effect on nitric oxide and nitrodilators [15]. Further beneficial vascular effects, particularly prevention of endothelial damage, would accrue from inhibition of the oxidation of LDL [67]. These actions could explain the observation that sciatic endoneurial blood flow is returned to normal by aminoguanidine treatment in diabetic rats [10].

Aldose reductase inhibitors could have mixed vascular-neuronal effects. Thus, prevention of changes in vessel contractility and relaxation [22] may improve nerve blood flow [21], giving similar benefits to those seen with vasodilators. Polyol pathway activity diverts glucose through the hexose monophosphate shunt, with a concomitant decrease in ATP synthesis [68]. Moreover, the glutathione cycle in mitochondria is NADPH dependent, and dysfunction would allow hydroxyl radical damage to cell membranes, which would also impair mitochondrial function and oxidative metabolism [42]. In addition to a deleterious effect on axons and Schwann cells, interference with ATP production also reduces endothelial synthesis of 
nitric oxide $[69,70]$. Thus, aldose reductase inhibitors would have a profound indirect protective effect against oxidative and metabolic stress.

In conclusion, anti-oxidant treatment prevents nerve dysfunction in experimental diabetes. The effects of many manipulations that improve nerve function can also be viewed as correcting oxidative stress by vascular and other mechanisms. It is, therefore, plausible that the short-term deleterious effects of diabetes reflect oxidative stress which may be manifested in the long-term as progressive damage [24] to neurons which could be of relevance to the aetiology of clinical neuropathy. Thus, anti-oxidant treatment may provide a potential therapeutic approach to diabetic neuropathy. The lower level of complications seen in developed compared to underdeveloped countries may relate in part to a higher dietary intake of anti-oxidants such as BHT [31].

Acknowledgements. This work was supported in part by a grant from the British Diabetic Association. E.K.M. is supported by a research studentship from Imperial Chemical Industries. We thank Drs. F. Carey and D. Mirrlees of Imperial Chemical Industries for discussion and encouragement, and Ms J.Stafford for nerve polyol analysis.

\section{References}

1. Tuck RR, Schmelzer JD, Low PA (1984) Endoneurial blood flow and oxygen tension in the sciatic nerves of rats with experimental diabetic neuropathy. Brain 107: 935-950

2. Cameron NE, Cotter MA, Low PA (1991) Nerve blood flow in early experimental diabetes in rats: relation to conduction deficits. Am J Physiol 261: E1-E8

3. Cameron NE, Cotter MA, Ferguson K, Robertson S, Radcliffe MA (1991) Effects of chronic $\alpha$-adrenergic receptor blockade on peripheral nerve conduction, hypoxic resistance, polyols, $\mathrm{Na}^{+}$$\mathrm{K}^{+}$-ATPase activity, and vascular supply in STZ-D rats. Diabetes 40: $1652-1658$

4. Cameron NE, Cotter MA, Robertson S (1992) Angiotensin converting enzyme inhibition prevents the development of muscle and nerve dysfunction and stimulates angiogenesis in streptozotocin-diabetic rats. Diabetologia 35: 12-18

5. Hotta N, Kakuta H, Fukasawa H et al. (1992) Effect of niceritol on streptezocin-induced diabetic neuropathy in rats. Diabetes 41: $587-591$

6. Cameron NE, Cotter MA, Robertson S (1989) Chronic low frequency electrical activation for one week corrects nerve conduction deficits in rats with diabetes of three months duration. Diabetologia 32: 759-761

7. Cameron NE, Cotter MA, Robertson S (1991) Essential fatty acid diet supplementation: effects on peripheral nerve and skeletal muscle function and capillarization in streptozocin-induced diabetic rats. Diabetes 40: 532-539

8. Julu POO (1990) $\psi$ linolenic acid: a novel remedy for diabetic neuropathy in experimental animals. In: Horrobin DF (ed) Omega- 6 essential fatty acids: pathophysiology and roles in clinical medicine. Liss, New York, pp 465-476

9. Tomlinson DR, Robinson JP, Compton AM, Keen P (1989) Essential fatty acid treatment - effects on nerve conduction, polyol pathway and axonal transport in streptozotocin diabetic rats. Diabetologia 32: 655-659

10. Kihara M, Schmelzer JD, Poduslo JF, Curran FF, Nickander KK, Low PA (1991) Aminoguanidine effect on nerve blood flow, vascular permeability, electrophysiology, and oxygen free radicals. Proc Natl Acad Sci USA 88: 6107-6111

11. Cameron NE, Cotter MA, Dines K, Love A (1992) Effects of aminoguanidine on peripheral nerve function and polyol path- way metabolites in streptozotocin-diabetic rats. Diabetologia 35: 946-950

12. Mayer JH, Tomlinson DR (1983) Prevention of defects in axonal transport and nerve conduction by oral administration of myoinositol or an aldose reductase inhibitor in streptozotocindiabetic rats. Diabetologia 25: 433-438

13. Cameron NE, Cotter MA, Robertson S (1989) The effect of aldose reductase inhibition on the pattern of nerve conduction deficits in diabetic rats. QJ Exp Physiol 74: 917-926

14. Baynes JW (1991) Role of oxidative stress in the development of complications in diabetes. Diabetes 40: 405-412

15. Bucala R, Tracey KJ, Cerami A (1991) Advanced glycosylation products quench nitric oxide and mediate defective endothelium-dependent vasodilation in experimental diabetes. J Clin Invest $87: 432-438$

16. Kumari K, Umar S, Bansal V, Sahib MK (1991) Inhibition of diabetes-associated complications by nucleophilic compounds. Diabetes 40: 1079-1084

17. Corbett JA, Tilton RG, Chang K et al. (1992) Aminoguanidine, a novel inhibitor of nitric oxide formation, prevents diabetic vascular dysfunction. Diabetes 41: 552-556

18. Lattimer SA, Sima AAF, Greene DA (1989) In vitro correction of impaired $\mathrm{Na}^{+}-\mathrm{K}^{+}$-ATPase in diabetic nerve by protein kinase Cagonists. Am J Physiol 256: E264-E269

19. Lambourne JE, Brown AM, Calcutt N, Tomlinson DR, Willars GB (1988) Adenosine triphosphatase in nerves and ganglia of rats with streptozotocin-induced diabetes or galactosaemia; effects of aldose reductase inhibition. Diabetologia 31: 379-384

20. Sredy J, Flam BR, Sawicki DR (1991) Adenosine triphosphatase activity in sciatic nerve tissue of streptozocin-induced diabetic rats with and without high dietary sucrose: effects of aldose reductase inhibitors. Proc Soc Exp Biol Med 197: 135-142

21. Yasuda H, Sonobe M, Yamashita M et al. (1989) Effect of prostaglandin $E_{1}$ analogue TFC 612 on diabetic neuropathy in streptozocin-induced diabetic rats comparison with aldose reductase inhibitor ONO2235. Diabetes 38: 832-838

22. Cameron NE, Cotter MA (1992) Impaired contraction and relaxation in aorta from streptozotocin-diabetic rats: role of polyol pathway activity. Diabetologia 35: 1011-1019

23. Schmelzer JD, Zochodne DW, Low PA (1989) Ischemic and reperfusion injury of rat peripheral nerve. Proc Natl Acad Sci USA 86: $1639-1642$

24. McCord JM (1985) Oxygen-derived free radicals in postischemic tissue injury. New Engl J Med 312: 159-163

25. Kashiwagi A, Kikkawa R (1992) Abnormal glutathione redox cycle in cultured human endothelial cells for the pathogenesis of diabetic vascular complications. In: Rifkin H, Colwell JA, Taylor SI (eds) Diabetes 1991, proceedings of the 14 th International Diabetes Federation Congress, Washington DC, 23-28 June 1991. Excerpta Medica, Amsterdam, New York, pp 679 682

26. Loven DH, Schedl H, Wilson $H$ et al. (1986) Effects of insulin and oral glutathione on glutathione levels and superoxide dismutase activities in organs of rats with streptozotocin-induced diabetes. Diabetes 35: 503-507

27. Low PA, Nickander KK (1991) Oxygen free radical effects in sciatic nerve in experimental diabetes. Diabetes 40: 873-877

28. Creighton MO, Trevithick JR (1979) Cortical cataract formation prevented by vitamin $\mathrm{E}$ and glutathione. Exp Eye Res 29: 689693

29. Trevethick JR, Creighton MO, Ross WM, Stewart-DeHaan JP, Sanwal M (1981) Modelling cortical cataractogenesis II. In vitro effects on the lens of agents preventing glucose- and sorbitol-induced cataracts. Can J Opthalmol 16: 32--38

30. Ross WM, Creighton MO, Trevithick JR, Stewart-DeHaan JP, Sanwal M (1983) Modelling cortical cataractogenesis IV. Induction by glucose in vitro or in diabetic rats: prevention and reversal by glutathione. Exp Eye Res 37: 559-573

31. Srivastava SK, Ansari NH (1988) Prevention of sugar-induced cataractogenesis in rats by butylated hydroxytoluene. Diabetes 37: $1505-1508$ 
32. Wilson GL, Patton NJ, McCord JM, Mullins DW, Mossman BT (1984) Mechanisms of streptozotocin- and alloxan-induced damage in rat B cells. Diabetologia 27: 587-591

33. Stribling D, Mirrlees DJ, Harrison HE, Earl DCN (1985) Properties of ICI 128,436, a novel aldose reductase inhibitor and its effects on diabetic complications in the rat. Metabolism 34: 336-344

34. Seneviratne KN, Peiris OA (1969) The effects of hypoxia on the excitability of the isolated peripheral nerves of alloxan-diabetic rats. J Neurol Neurosurg Psychiat 32: 462-469

35. Bravenboer B, Kapelle AC, Hamers FPT, van Buren T, Erkelens DW, Gispen WH (1992) Potential use of glutathione for the prevention and treatment of diabetic neuropathy in the streptozotocin-induced diabetic rat. Diabetologia 35: 813-817

36. Greene DA, De Jesus PV, Winegrad AI (1975) Effects of insulin and dietary myoinositol on impaired peripheral motor nerve conduction velocity in acute streptozotocin diabetes. J Clin Invest 55: $1326-1336$

37. Eliasson SG (1964) Nerve conduction changes in experimental diabetes. J Clin Invest 43: 2352-2358

38. Suzuki K, Saito N, Sakata Y, Toyota T, Goto Y (1990) A new prostaglandin $E_{1}$ analogue (TFC-612) improves the reduction in motor nerve conduction velocity in spontaneously diabetic GK (Goto-Kakizaki) rats. Prostaglandins 40: 463-471

39. Sima AAF, Prashar A, Zhang W-X, Chakrabarti S, Greene DA (1990) Preventive effect of long-term aldose reductase inhibition (ponalrestat) on nerve conduction and sural nerve structure in the spontaneously diabetic Bio-Breeding rat. J Clin Invest 85 : $1410-1420$

40. Robertson S, Cameron NE, Cotter MA, Dines K (1992) Timecourse of reversal of nerve conduction deficits by aldose reductase inhibition, evening primrose oil, chronic electrical stimulation, and angiotensin converting enzyme inhibition in streptozotocindiabetic rats. Diabetic Med 9 [Suppl 2]: P58 (Abstract)

41. Cotter MA, Cameron NE, Robertson S (1991) Effects of increased electrical activity on peripheral nerve function in streptozotocin-diabetic rats. Diabetologia 34 [Suppl 2]: A50 (Abstract)

42. Price DE, Airey CM, Alani SM, Wales JK (1988) Effect of aldose reductase inhibition on nerve conduction velocity and resistance to ischemic conduction block in experimental diabetes. Diabetes 37: 969-973

43. Cameron NE, Cotter MA (1992) Dissociation between biochemical and functional effects of the aldose reductase inhibitor ponalrestat on peripheral nerve in diabetic rats. Br J Pharmacol 107: 939-944

44. Lockett MJ, Tomlinson DR (1992) The effects of dietary treatment with essential fatty acids on sciatic nerve conduction and activity of the $\mathrm{Na}^{+} / \mathrm{K}^{+}$pump in streptozotocin-diabetic rats. Br J Pharmacol 105: 355-360

45. Low PA, Tuck RR, Takeuchi M (1987) Nerve microenvironment in diabetic neuropathy. In: Dyck PJ, Thomas PK, Asbury AK, Winegrad AI, Porte D (eds) Diabetic neuropathy. Saunders, Philadelphia, pp 266-278

46. Pette D, Smith ME, Staudte HW, Vrbová G (1973) Effects of long-term electrical stimulation on some contractile and metabolic characteristics of fast and slow rabbit muscles. Pflügers Archiv 378: 251-257

47. Reed DJ (1990) Glutathione: toxicological implications. Annu Rev Pharmacol Toxicol 30: 603-631

48. Vlassara H, Brownlee M, Cerami A (1983) Excessive non enzymatic glycosylation of peripheral and central nervous system myelin components in diabetic rats. Diabetes 32: 670-674

49. Cullum NA, Mahon J, Stringer K, McLean WG (1991) Glycation of rat sciatic nerve tubulin in experimental diabetes mellitus. Diabetologia 34: 387-389

50. Andrews HE, Brukdorfer KR, Dunn RC, Jacobs M (1987) Lowdensity lipoproteins inhibit endothelium-dependent relaxation in rabbit aorta. Nature 327: 237-239

51. Morel DW, Chisolm G (1989) Antioxidant treatment of diabetic rats inhibits lipoprotein oxidation and cytotoxicity. J Lipid Res 30: $1827-1834$
52. Evensen SA, Galdal KS, Nilsen E (1983) LDL-induced cytotoxicity and its inhibition by anti-oxidant treatment in cultured human endothelial cells and fibroblasts. Atherosclerosis 49: $23-$ 30

53. Lyons TJ (1991) Oxidised low density lipoproteins - a role in the pathogenesis of atherosclerosis in diabetes. Diabetic Med 8: 411419

54. Moore SA, Bohlen HG, Miller BG, Evan AP (1985) Cellular and vessel wall morphology of cerebral cortical arterioles after shortterm diabetes in adult rats. Blood Vessels 22: $265-277$

55. Peiper GM, Gross GJ (1988) Oxygen free radicals abolish endothelium-dependent relaxation in diabetic rat aorta. Am J Physiol 255: $\mathrm{H} 825-\mathrm{H} 833$

56. Kamata K, Miyata N, Kasuya Y (1989) Impairment of endothelium-dependent relaxation and changes in levels of cyclic GMP in aorta from streptozotocin-induced diabetic rats. Br J Pharmacol 97: 614-618

57. Oyama Y, Kawasaki H, Hattori Y, Kanno M (1986) Attenuation of endothelium-dependent relaxation in aorta from diabetic rats. Eur J Pharmacol 131: 75-78

58. Ward KK, Low PA, Schmelzer JD, Zochodne DW (1989) Prostacyclin and noradrenaline in peripheral nerve of chronic experimental diabetes in rats. Brain 112: 197-208

59. Lands WEM (1985) Mechanisms of action of anti-inflamatory drugs. Adv Drug Res 14: 147-163

60. Gryglewski RJ, Palmer RMJ, Moncado S (1986) Superoxide anion is involved in the breakdown of endothelium-derived vascular relaxing factor. Nature 320: 454-456

61. Hattori Y, Kawasaki H, Kazuhiro A, Kanno M (1991) Superoxide dismutase recovers altered endothelium-dependent relaxation in diabetic rat aorta. Am J Physiol 261: H1086-H1094

62. Kiff RJ, Gardiner SM, Compton AM, Bennett T (1991) The effects of endothelin-1 and $\mathrm{N}^{\mathrm{G}}$-nitro-L-arginine methyl ester on regional haemodynamics in conscious rats with streptozotocin-induced diabetes mellitus. Br J Pharmacol 103: 1321-1326

63. Kiff RJ, Gardiner SM, Compton AM, Bennett T (1991) Selective impairment of hindquarters vasodilator responses to bradykinin in conscious Wistar rats with streptozotocin-induced diabetes mellitus. Br J Pharmacol 103: 1357-1362

64. Morff RJ (1990) Microvascular reactivity to norepinephrine at different arteriolar levels and durations of streptozocin-induced diabetes. Diabetes 39: 354-360

65. Tomlinson KC, Gardiner SM, Hebden RA, Bennett T (1992) Functional consequences of streptozotocin-induced diabetes mellitus, with particular reference to the cardiovascular system. Pharmacol Rev 44: 103-150

66. Monafo WM, Eliasson SG, Shimazaki S, Sugimoto H (1988) Regional blood flow in resting and stimulated sciatic nerve of diabetic rats. Exp Neurol 99: 607-614

67. Picard S, Parthasarathy S, Fruebis J, Witztum JL (1992) Aminoguanidine (AMGN) inhibits LDL oxidative modification. Diabetes 41 [Suppl 1]: $17 \mathrm{~A}$ (Abstract)

68. Davidson WS, Murphy DG (1985) Aldehyde reductases and their involvement in muscular dystrophy. In: Flynn G (ed) Enzymology of carbonyl metabolism 2: aldehyde dehydrogenase, aldo-keto reductase and alcohol dehydrogenase. Liss, New York, pp 251-263

69. Griffith TM, Edwards DH, Newby AC, Lewis MJ, Henderson $\mathrm{AH}$ (1986) Production of endothelium-derived relaxant factor is dependent on oxidative phosphorylation and extracellular calcium. Cardiovasc Res 20:7-12

70. Weir CJ, Gibson IF, Martin W (1991) Effects of metabolic inhibitors on endothelium-dependent and endothelium-independent vasodilation of rat and rabbit aorta. Br J Pharmacol 102: 162-166

Received: 28 September 1992

and in revised form: 23 November 1992

Dr. N.E.Cameron, Department of Biomedical Sciences

University of Aberdeen, Marischal College

Aberdeen AB9 1 AS, Scotland, UK 